\title{
Article \\ Soft Jumping Robot Using Soft Morphing and the Yield Point of Magnetic Force
}

\author{
Gang-Hyun Jeon and Yong-Jai Park*(1) \\ Robot \& Mechanism LAB, Biohealth-Machinery Convergence Engineering, Kangwon National University, \\ Chuncheon 24341, Gangwon, Korea; wjsrkdgus1994@gmail.com \\ * Correspondence: yjpark@kangwon.ac.kr; Tel.: +82-33-250-6371
}

Citation: Jeon, G.-H.; Park, Y.-J. Soft Jumping Robot Using Soft Morphing and the Yield Point of Magnetic Force. Appl. Sci. 2021, 11, 5891. https:// doi.org/10.3390/app11135891

Academic Editor:

Alessandro Gasparetto

Received: 31 May 2021

Accepted: 23 June 2021

Published: 24 June 2021

Publisher's Note: MDPI stays neutral with regard to jurisdictional claims in published maps and institutional affiliations.

Copyright: (c) 2021 by the authors. Licensee MDPI, Basel, Switzerland. This article is an open access article distributed under the terms and conditions of the Creative Commons Attribution (CC BY) license (https:/ / creativecommons.org/licenses/by/ $4.0 /)$.

\begin{abstract}
In this paper, soft-morphing, deformation control by fabric structures and soft-jumping mechanisms using magnetic yield points are studied. The durability and adaptability of existing rigid-base jumping mechanisms are improved by a soft-morphing process that employs the residual stress of a polymer. Although rigid body-based jumping mechanisms are used, they are driven by multiple components and complex structures. Therefore, they have drawbacks in terms of shock durability and fatigue accumulation. To improve these problems, soft-jumping mechanisms are designed using soft polymer materials and soft-morphing techniques with excellent shock resistance and environmental adaptability. To this end, a soft jumping mechanism is designed to store energy using the air pressure inside the structure, and the thickness of the polymer layer is adjusted based on the method applied for controlling the polymer freedom and residual stress deformation. The soft jumping mechanism can transfer energy more efficiently and stably using an energy storage and release mechanism and the rounded ankle structure designed using soft morphing. Therefore, the soft morphing and mechanisms of energy retention and release were applied to fabricate a soft robot prototype that can move in the desired direction and jump; the performance experiment was carried out.
\end{abstract}

Keywords: soft robot; soft jumping robot; soft morphing; residual stress; magnetic yield point

\section{Introduction}

The development of Fourth Industrial Revolution technologies has resulted in the extensive application of these technologies in various fields and industries; various robots and production processes have been recently developed for more efficient and safe work. Robots produced through new materials and new manufacturing methods are applied to perform various tasks that were performed manually. However, with an increase in the number of robots replacing human intervention in various fields and environments, the problem of robot control and driving in various environments is gaining considerable research attention. Robots made up of rigid bodies are designed and controlled according to a particular process or environment, and therefore, there is a problem in that the design or control of the drive part must be changed when the environment of use changes. Hightech and high-performance robots are being developed, such as Cheetah [1] at MIT and Big Dog [2] at Boston Dynamics to develop a robot that can be applied immediately to multiple environments without changing the design or control of the drive. However, these robots have limitations in terms of accessibility, manufacturing process, and the high cost of the technology required to build the robot. Therefore, a new type of robot is actively being developed to improve the adaptability and durability of robots and to build highly accessible robots that can be efficiently applied to various environments without changing the design or control of the drives. Soft robots are made of soft materials, such as polymers, that absorb shocks well and are adaptable to objects. Further, these materials have advantages in that they can be used to build robots that can be applied to various 
environments with simpler control. However, it is difficult to apply a drive that requires instantaneous release of great force, such as a jump, to a soft robot.

To solve these problems and further highlight the advantages of soft robots, various soft robots and driving parts are being developed that can be integrated while preserving the characteristics and advantages of soft robots. The related studies include driving methods that employ properties of substances such as SMA (shape memory alloy) and SMP (shape memory polymer) [3-7] that deform in response to specific conditions such as temperature and light, soft robots [8-10] that use instantaneous energy generated by the explosion of gas compounds, and robots [11,12] that use mechanical designs [13-17]. Among biomimetic robots [18-24], soft morphing [25-27], which creates residual stresses in structures or inserts actuators to change shape [28,29], and robots that use soft materials and pneumatic drive [30] can be applied without significantly degrading their performance.

In this paper, the thickness of the polymer layer is adjusted by the needed shape. Further, a one-way tensile force is applied in the soft morphing process for stacking different kinds of polymers and forming residual stresses on the polymer. The non-stretching fabric material is inserted in layers to control the deformation and shape of polymers with high degrees of freedom to suit their needs. In addition, we produced prototypes of soft robots that could overcome various environments such as crawling and jumping using soft morphing, magnetic yield, and air chambers inserted inside the structure through the storage and release of energy implemented by the soft robot. The final goal of this research is to install an air pressure drive system inside a soft jumping robot and enable the robot to perform tasks such as investigating and transmitting light objects on behalf of humans.

\section{Fabrication of Polymer Structures and Formation of Residual Stresses}

\subsection{Soft Morphing}

Soft morphing structures are mostly made of soft materials with no restrictions on the degrees of freedom, and they are characterized by continuous and soft movement. By using the continuous soft movement of soft morphing, one can not only achieve natural and flexible movements that cannot be realized by robots with rigid bodies, but it can also help overcome limitations of rigid materials that are vulnerable to impact. In the case of polymers, even if external shocks such as shock or distortion are applied, they absorb shock smoothly and do not break. Furthermore, the hardness of the soft material forming the structure can be adjusted to a desired degree of rigidity. Therefore, various studies on soft morphing [27-29] have been actively conducted owing to these advantages.

\subsection{Residual Stresses}

Residual stress is defined as the energy applied to an object that remains indefinitely in the object while retaining the strength and direction of the residual stress. Because of residual stress, the object can have various forms and numbers of stable states. In this paper, the residual stress is induced in a polymer structure to minimize the driving part by steady state deformed by residual stress and produce a soft mechanism that highlights the advantages of soft morphing. Through residual stress induced in a polymer structure the robot's shape and jumping motion can be completed and a part of the recovery process can be achieved. To produce a ductile polymer structure, Cubicon's Style NEO-A22 model and PLA $+3 \mathrm{D}$ printer filament was used to produce $100 \%$ molds of interior filling $(0.014 \mathrm{~m} \times 0.003 \mathrm{~m})$. A suitable amount of smooth-on soft polymer, a curing accelerator Plat Cat, and Ecoflex0050 were mixed into the mold; depopulation was carried out at a pressure of $0.1 \mathrm{MPa}$ using a vacuum depopulator for $10 \mathrm{~min}$. After the deformation, the liquid polymer was poured into the mold, and an acrylic plate and a $1.5 \mathrm{~kg}$ weight were placed on it. Further, it was cured in an oven at $55^{\circ} \mathrm{C}$ for $60 \mathrm{~min}$. To make a polymer structure, the liquid polymer must be cured by mixing main material $\mathrm{A}$ and sub material $\mathrm{B}$. The mixing ratio of the main and sub materials to fabricate polymer structures used in this paper is summarized in Table 1. 
Table 1. Mixing ratio of liquid polymer.

\begin{tabular}{cc}
\hline Material & Percent (\%) \\
\hline Main material A & 49.5 \\
Sub material B & 49.5 \\
Cure accelerator & 1 \\
\hline
\end{tabular}

To induce residual stress inside the polymer structure using the EcoFlex0050 liquid polymer material, the elasticity of the polymer was used to stretch the polymer structure. When the polymer structure is fixed in a tensile state, the elastic stresses from inside the polymer structure maintain the stress generated by the elastic resilience and form residual stress inside. This is conducted to the maintain residual stress in a state where the structure is stretched and fixed. Other polymer structures are bonded to the upper part to interfere with the contraction of the lower polymer structures in a state where the stress caused by the elastic resilience is not eliminated. Therefore, the lower polymer structure is stretched to prevent the stress formed inside from being eliminated by the structure bonded to the upper part and the stress formed inside (Figure 1).

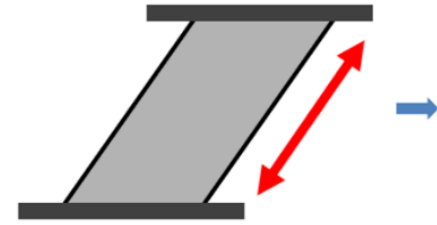

Stretch

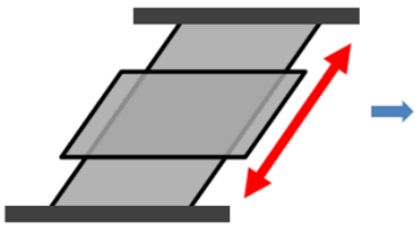

Bonding

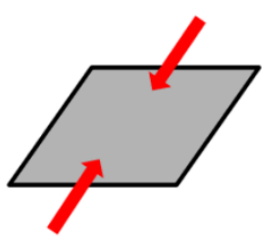

Restoration force

Figure 1. Process of forming residual stresses on a polymer structure.

\section{Fabrication of Deformation Structures Caused by Residual Stresses}

The lower polymer structure must be fixed in a tensile state until the end of the upper polymer bonding process to form a stable residual stress inside the polymer structure. A device (Figure 2) was set to hold the polymer structure in a tensile state to maintain the tensile state of the lower polymer structure throughout the work process.

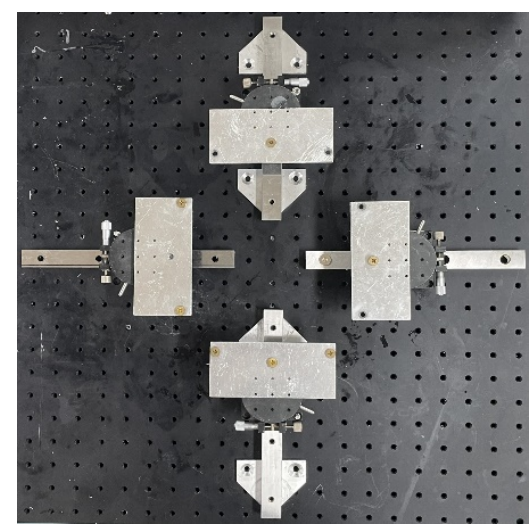

Figure 2. Process of forming residual stresses on a polymer structure.

First, a perforated metal plate was set to hold the polymer structure securely to the floor without shaking. Next, we fix the polymer structure $0.005 \mathrm{~m}$ away from both ends of the EcoFlex0050 and it is stretched and secured at $0.02 \mathrm{~m}$. The tensile and fixed polymer structures prevent the stress caused by the elastic resilience from being eliminated in the manufacturing process and allow the stable manufacture of upper polymer structures. When the lower polymer structure is stretched and fixed, as shown in Figure 3a, the mold 
of upper polymer structure is attached to the lower polymer structure. The flat plate is laid in the empty space under the polymer structure so that work can be conducted more accurately. Considering the Poisson ratio of the polymer structure so that the polymer structure can be deformed uniformly, the center of the mold and the center of the polymer structure are bonded in the same way, as shown in Figure 3b.

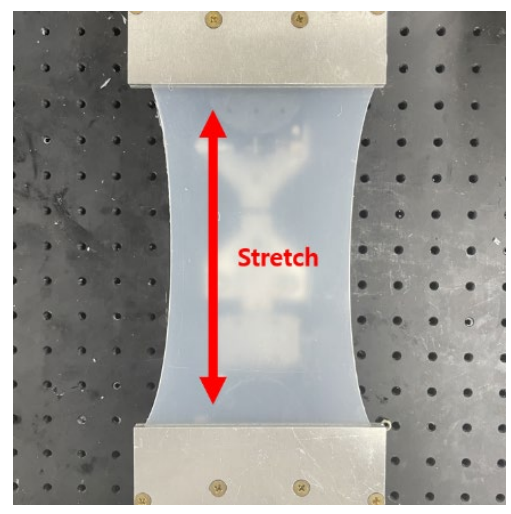

(a)

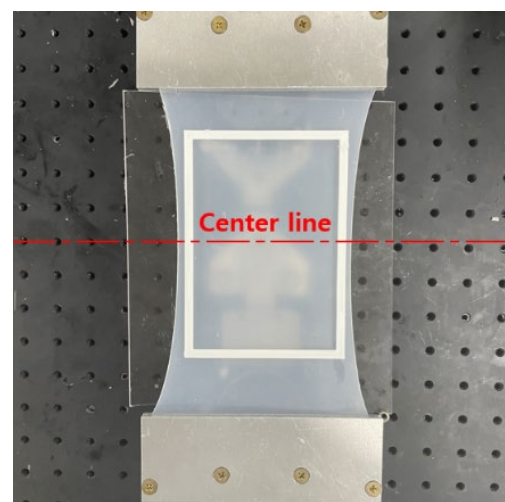

(b)

Figure 3. Process of forming residual stresses on a polymer structure. (a) Stretch-fixed lower polymer structure; (b) working position of upper polymer structure.

Dragon Skin Fx pro liquid polymer, which has low viscosity and higher hardness compared to that of EcoFlex0050, is used to resist shrinkage. To remove bubbles, a $367.75 \mathrm{~W}$ vacuum chamber was used for $7 \mathrm{~min}$ to defoaming at a pressure of $10^{5} \mathrm{~Pa}$. The acrylic plate and $1.5 \mathrm{~kg}$ weight were raised and cured at $23^{\circ} \mathrm{C}$ for $60 \mathrm{~min}$ to prevent the inflow of dust substances into the polymer structure and to ensure the uniform surface of the polymer structure. Finally, structures modified by residual stress as shown in Figure 4 were constructed.

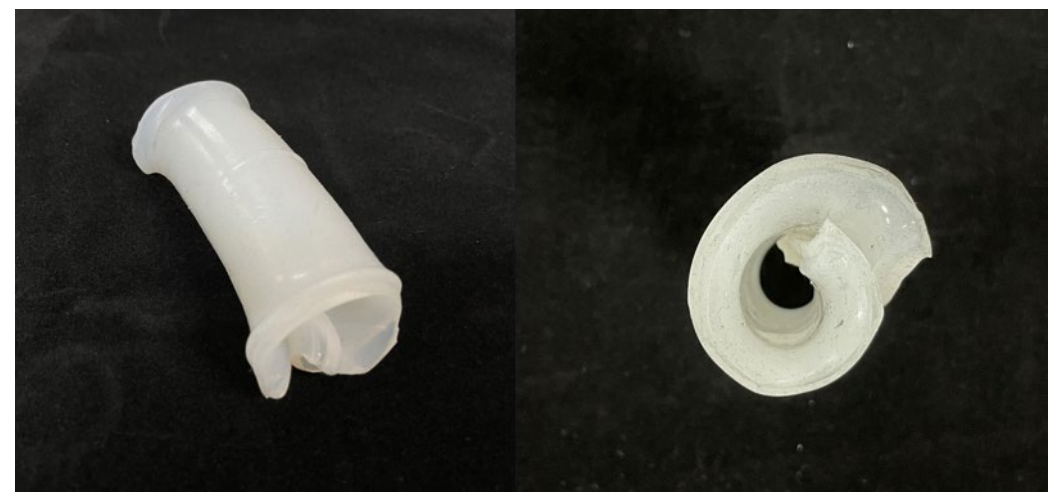

Figure 4. Structures deformed by residual stress.

\section{Deformation of Soft Morphing Structures According to the Conditions of Lower Polymer}

To determine the effect of tensile stress, elasticity, and thickness degree of the polymer structure on the deformation of the structure, the tensile property, elasticity, and thickness of lower polymer structure are changed when manufacturing the polymer structure. The vacuum defoaming time and curing time of the material and mixing ratio of the polymer structure are set to the same value and Dragon skin Fx pro was used for the upper polymer structure. The properties of the material used in the experiment are shown in Table 2.

Decreasing the tensile force $0.02 \mathrm{~m}$ to $0.01 \mathrm{~m}$ of the lower polymer structure (Figure $5 \mathrm{a}, \mathrm{b}$ ) causes a lower deformation of the polymer structure, which decreases the stress-energy 
generated inside the polymer structure. The decrease in the stress energy stored in the lower polymer structure causes a decrease in the stress asymmetry of the upper and lower polymer structures. Thus, the greater the stress asymmetry of the upper and lower polymer structures, the greater is the deformation rate of the final polymer structures, and the greater is the tensile degree of the lower polymer structures. If the elasticity of the lower polymer structure decreases by changing the material from EcoFlex0050 to EcoFlex0030 (Figure 5a,c), lower stress caused by the elastic resilience is formed inside the polymer structure during the tensile process. The deformation rate of the final polymer structure is lower because the decreased stress stores less stress internally than the existing lower polymer structure. When the tensile strength is the same as that of the raw material, the deformation rate of the final polymer structure becomes lower because the elastic restoring force decreased when the lower polymer structure is made thinner (Figure 5a,d). The experiments were carried out to verify the effect of various values of the tensile stress, elasticity, and thickness tests on the strain. When the tensile stress, elasticity, and thickness value of the lower polymer structure increases, the stress of the lower polymer also increases. Therefore, the greater the stress of the lower polymer structure is used, the greater the strain of the soft morphing structure is presented. The higher strain has the advantage of increasing a dynamic performance of a jumping robot. As a result, the $0.003 \mathrm{~m}$-thick EcoFlex0050 was stretched by $0.02 \mathrm{~m}$ to build the soft jumping robot as the lower polymer structure. The upper polymer structure has been made by Dragon skin Fx pro.

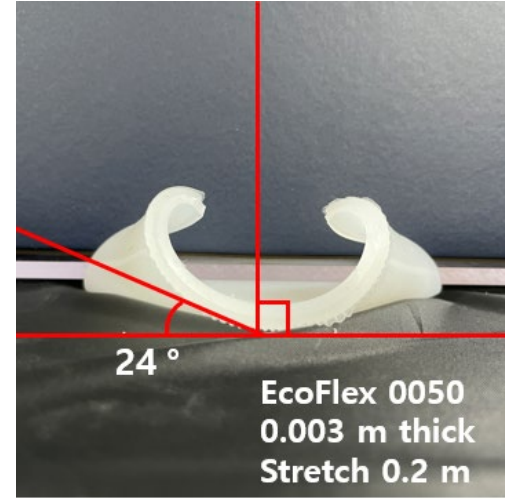

(a)

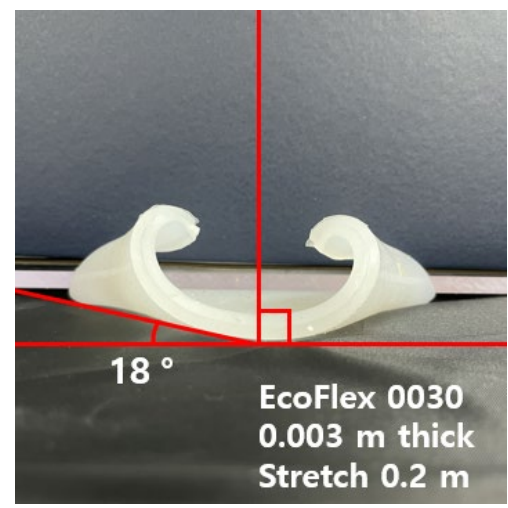

(c)

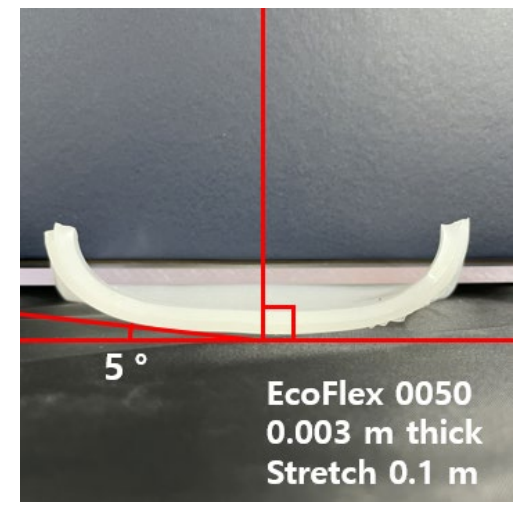

(b)

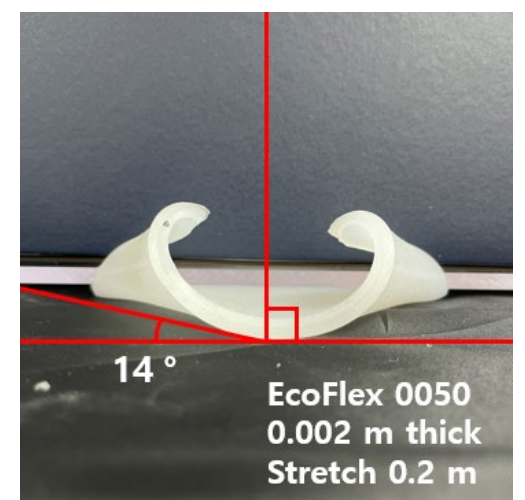

(d)

Figure 5. Differences in the strain of the polymer structures based on tensile stress. (a) Polymer structure made with EcoFlex0050, stretched to $0.2 \mathrm{~m}, 0.003 \mathrm{~m}$ thick; (b) polymer structure made with EcoFlex0050, stretched to $0.1 \mathrm{~m}, 0.003 \mathrm{~m}$ thick; (c) polymer structure made with EcoFlex0030, stretched to $0.2 \mathrm{~m}, 0.003 \mathrm{~m}$ thick; (d) polymer structure made with EcoFlex 0050, stretched to $0.2 \mathrm{~m}$, $0.002 \mathrm{~m}$ thick. 
Table 2. Properties of the material used in the experiment.

\begin{tabular}{cccc}
\hline Material & EcoFlex0050 & EcoFlex0030 & Dragon Skin Fx Pro \\
\hline Shore hardness & $00-50$ & $00-30$ & 2 \\
\hline Mixed viscosity & $8000 \mathrm{cps}$ & $3000 \mathrm{cps}$ & $18,000 \mathrm{cps}$ \\
\hline Tensile strength & $315 \mathrm{psi}$ & $200 \mathrm{psi}$ & $288 \mathrm{psi}$ \\
\hline Elongation at break & $980 \%$ & $900 \%$ & $763 \%$ \\
\hline
\end{tabular}

\section{Soft Jumping Mechanism Using Magnetic Force}

\subsection{Pneumatic Drive Fabrication}

A pneumatic drive is formed inside the polymer structure to drive the polymer deformed by the residual stress formed by the tensile-bonding process. In the manufacturing process of polymer structures deformed by residual stress, the polymer is stretched to $0.02 \mathrm{~m}$ and the mold for the upper structure is raised on the fixed lower polymer structures. Then, some adhesives are applied to the middle of the $0.06 \mathrm{~m} \times 0.02 \mathrm{~m} \times 0.001 \mathrm{~m}$ prosthesis and the prosthesis is bonded as shown in Figure $6 a$ to prevent liquid polymers from moving out during the manufacture of the superstructure. Therefore, the upper part of the prosthesis is in the center where the Poisson's ratio is highest, and deformation occurs the most so that the effective deformation can be obtained because of the high deformation rate. A thin layer of petrolatum is applied to the prosthesis inserted for forming the air chamber so that the air chamber can be pulled out without damage. After the upper polymer structure is completely cured, the top $0.002 \mathrm{~m}$ part of the prosthesis inserted into the air chamber mold is cut to remove the prosthesis from the air chambers, as in Figure $6 \mathrm{~b}$. The incisions of the air chamber are sealed with Dragon skin Fx pro after the pneumatic tube is inserted in the process of controlling the degrees of freedom using fabric materials.

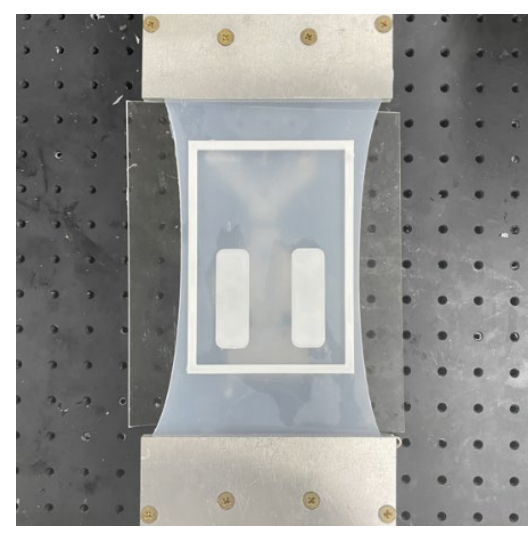

(a)

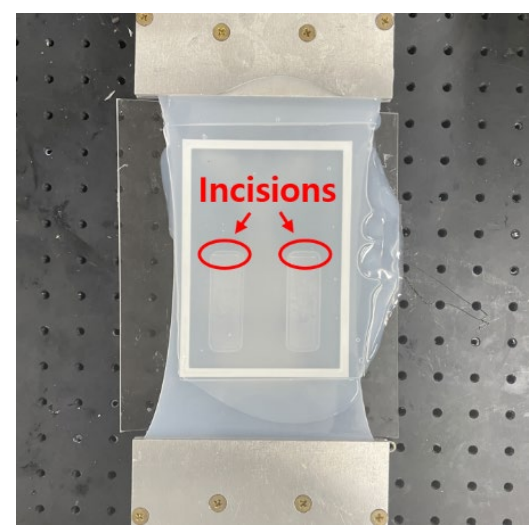

(b)

Figure 6. Air chamber molding inside the polymer structure. (a) Mold and prosthesis work position for upper polymer structure work. (b) incisions for the removal of the upper polymer structure prosthesis.

\subsection{Polymer Freedom Agent Using Fabric Material}

In the process of manufacturing the upper polymer structure, the incision of the air chamber made by inserting the prosthesis is sutured to control the degrees of freedom of the polymer. Dragon skin Fx pro, the same material as the material used in the manufacture of the upper polymer, is coated thinly on the upper polymer structure, and a fabric material that does not extend in the upper and lower directions of the structure is placed. Then, the liquid Dragon skin Fx Pro is applied to the fabric material, which is fully absorbed by the fabric. Acrylic plates are then placed on the fabric material to ensure a smooth surface and prevent the inflow of dust substances. A $1.5 \mathrm{~kg}$ weight is placed on the acrylic plate so that the acrylic plate can form a smooth surface; it is secured by supporting the left and right 
sides to prevent slipping during the solidification process. After the solidification process, a pneumatic tube is inserted by making a $0.005 \mathrm{~m}$ incision at the top, as in removing the prosthesis of the air chamber. After the pneumatic tube is inserted, a Dragon skin Fx pro is applied at the joint for sealing.

The manufactured soft pneumatic drive operates in a folded and extended form depending on the presence or absence of air injection designed inside the polymer structure, as shown in Figure $7 \mathrm{a}, \mathrm{b}$.

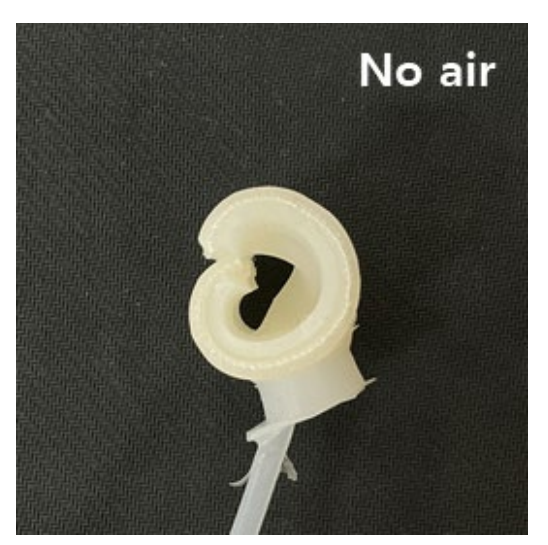

(a)

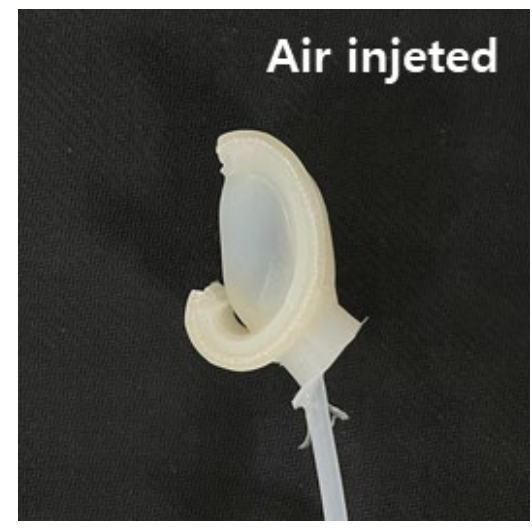

(b)

Figure 7. Movement of soft mechanisms by air injection. (a) State when air is not injected into the soft mechanism; (b) state when air is injected into the soft mechanism.

The completed composite polymer structure is shown in Figure 8. The lower polymer structure is tensile to form elastic stress. Further, the lower polymer structure is resistant to contraction, and therefore, the stress formed in the lower structure remains inside without complete resolution. In the middle of the polymer structure, there is an air chamber for the pneumatic drive. In addition, there is a fabric structure for shape control of the air chamber on top of the polymer structure.

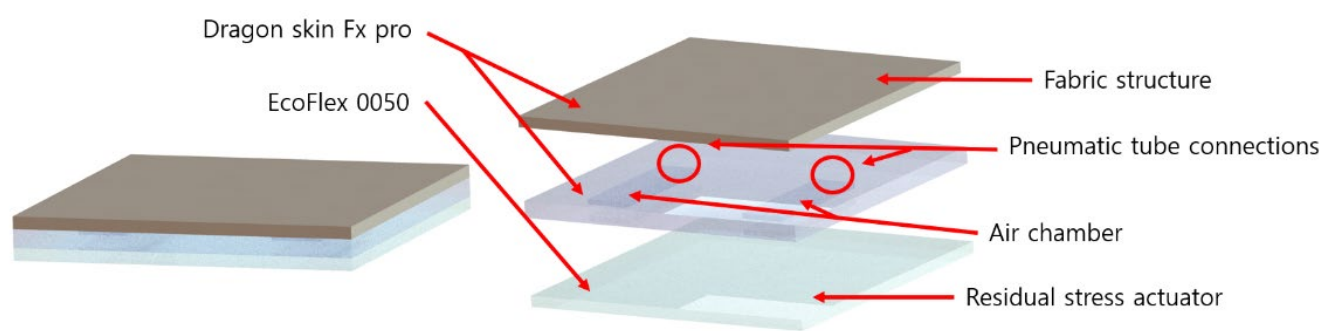

Figure 8. Decomposition of soft drive mechanisms.

\subsection{Energy Storage Using Magnetism}

We used permanent magnetism as a method to store energy inside a soft jumping mechanism. Permanent magnets are attached to both ends of the soft jumping mechanism as shown in Figure 9a,b.

Owing to the gravitational force of the attached permanent magnet, the air chamber cannot expand to a certain extent and produces pressure-induced energy inside. The power depends on the distance between the permanent magnets attached to both ends and it is given as:

$$
F_{z}=-\frac{\pi \mu_{0} M^{2}}{4} R^{4}\left[\frac{1}{x^{2}}+\frac{1}{(x+2 t)^{2}}-\frac{2}{(x+t)^{2}}\right]
$$


The approximation can be obtained through:

$$
F_{z}=-\frac{-3 \pi \mu_{0} M^{2}}{2} R^{4} t^{2} \frac{1}{x^{4}}
$$

when thickness $t$ is less than the distance $x$ between the magnets. Equations (1) and (2) are presented and derived in [31].

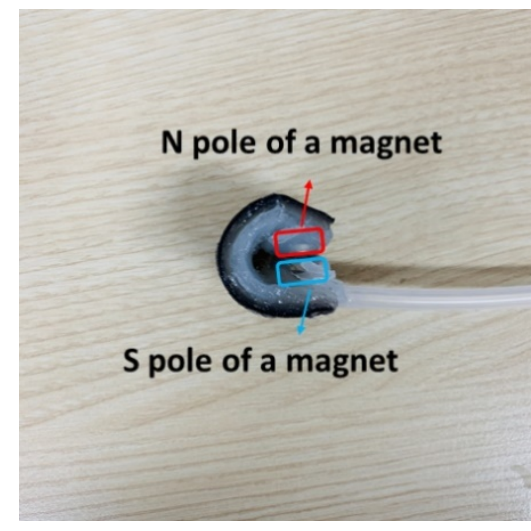

(a)

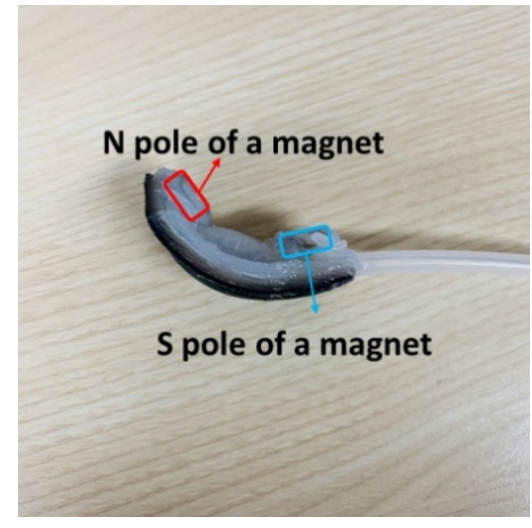

(b)

Figure 9. Energy storage using permanent magnets. (a) No air is injected in the air chamber; (b) air is injected in the air chamber.

In Equations (1) and (2), $F_{z}$ represents the magnet pulling force $(\mathrm{N}), \pi$ denotes the circular constant, $\mu_{0}$ its permeability, $M$ represents magnetization, $R$ denotes the radius of the magnet, $x$ denotes the distance between the permanent magnets, and $t$ denotes the thickness of the permanent magnet. However, the closer the distance between permanent magnets, the less accurate are Equations (1) and (2). Thus, Equations (1) and (2) are not suitable for this study. To solve the problem, the attraction of permanent magnets corresponding to the distance was confirmed and the approximate value was obtained. A permanent magnet with a length of $0.01 \mathrm{~m}$, width of $0.02 \mathrm{~m}$ and thickness of $0.003 \mathrm{~m}$ was used in the experiment; the maximum weight lifted by the magnet was measured according to the distance. The result of the experiment is shown in Figure 10.

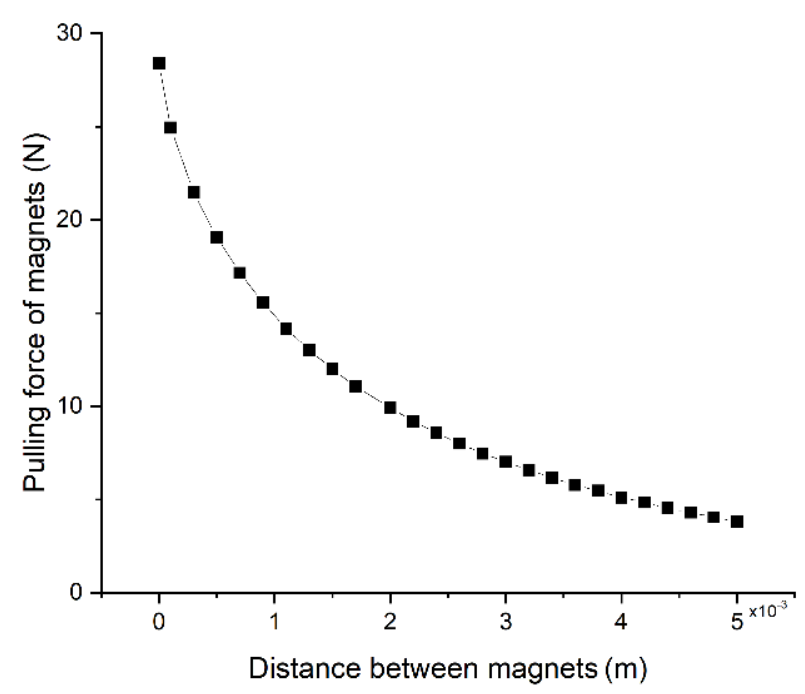

Figure 10. Pulling force of magnet according to distance. 
Based on the results of the experiment, a numerical interpretation was conducted using MATLAB (MathWorks). The traction force of the permanent magnet used in the experiment can be expressed as

$$
F_{m}=A e^{(-B x)}
$$

where $F_{m}$ denotes the weight that the magnet lifts; for $A$, it is $25.06 ; B ; 0.44 . \mathrm{R}^{2}$ denotes coefficient of determination of Equation (3) and it is 0.9752 . Through this, the approximate energy stored in the air chamber is confirmed when using permanent magnets.

\subsection{Emission of Energy Using Magnetic Yield Points}

When air is injected into the air chamber inside the soft jumping mechanism, the air chamber expands. If more than a certain amount of air is injected, the permanent magnets attached to both ends prevent the expansion of the air chamber, and this increases the pressure inside the air chamber. The magnitude of the force exerted by the air chamber can be expressed as shown in:

$$
F=\Delta P \times A
$$

In Equation (4), $F$ denotes the magnitude of the force on the air chamber, $\Delta P$ denotes amount of pressure change inside the air chamber and $A$ denotes the cross-sectional area of the magnet pushed out by the air chamber.

The volume of the air chamber designed inside the soft jumping mechanism is length of $0.06 \mathrm{~m}$, width of $0.03 \mathrm{~m}$ and thickness of $0.001 \mathrm{~m}$. The permanent magnets (length $=0.01 \mathrm{~m}$; width $=0.02 \mathrm{~m}$; thickness $=0.003 \mathrm{~m}$ ) are attached to both ends of the soft jumping mechanism. The air chamber expands until about $0.02 \mathrm{~L}$ of air is injected, and the magnetic field is induced when $0.035 \mathrm{~L}$ of air is injected as shown in Figure 11.

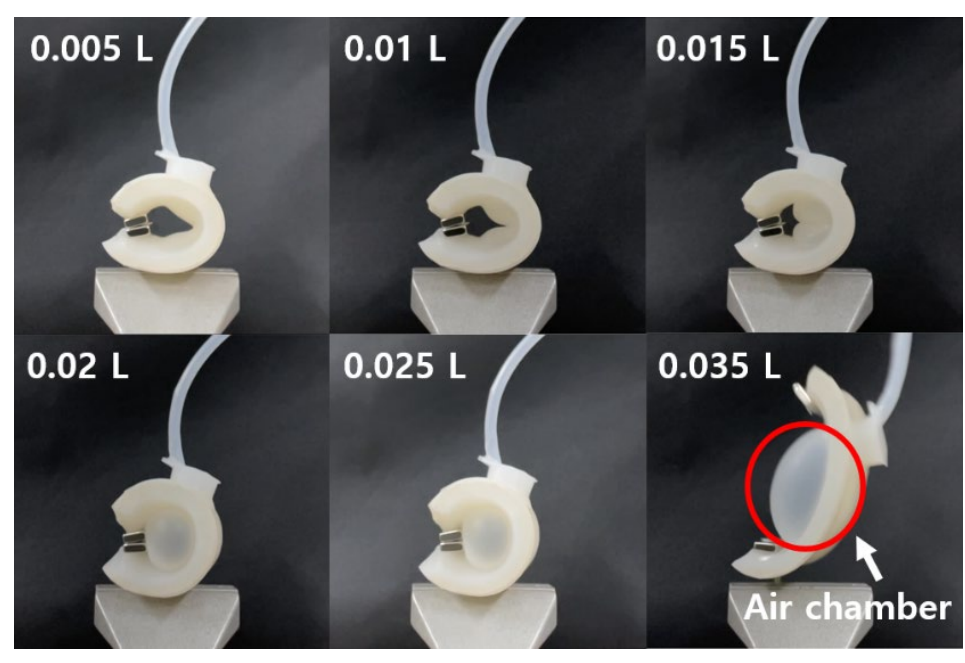

Figure 11. Pulling force of magnet according to distance.

According to Equations (3) and (4), the force of compressed air in the air chamber is $11.32 \mathrm{~N}$, and the force of permanent magnets attached to soft jumping mechanism in distance $0.0015 \mathrm{~m}$ is $12.95 \mathrm{~N}$. The actual measured distance between the permanent magnets is $0.0015 \mathrm{~m}$. Although the obtained force of the air chamber was lower than that of the permanent magnet, the magnetic yield point was reached, resulting in jumping. It is because the body of the soft jumping mechanism acts as a lever at the yield point of the magnet, as shown in Figure 12. As the magnet on the upper side rotates, the actual magnetic force becomes lower compared to the calculated magnetic force. 


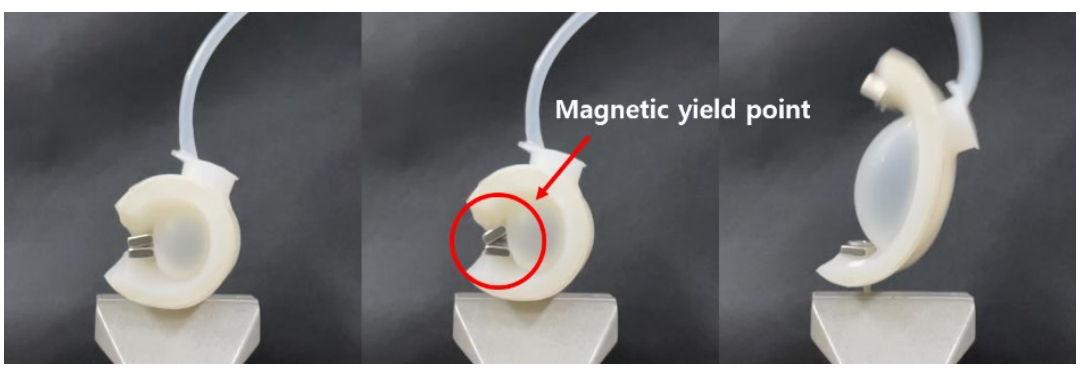

Figure 12. Movement of soft jumping mechanism at the magnetic yield point.

\section{Soft Jumping Robot Fabrication Using Magnetic Surrender}

\subsection{Shape Regulation through Residual Stress Control by Site}

Additional techniques are applied to the manufacturing stage of polymer structures deformed by residual stress to make soft jumping robots more efficient. Experiments conducted in Section 2.2 of this study confirmed that the residual stress stored in the polymer varies depending on the thickness of the polymer; i.e., the deformation rate varies depending on the thickness of the polymer. The thickness is adjusted as shown in Figure 13 so that the upper structure can adjust the residual stress inside the polymer structure to obtain the proper shape of the soft robot in the manufacturing stage of the polymer structure deformed by residual stress without additional drive design. Owing to the residual stress of the foot and body parts of the soft jumping robot, which are controlled by thickness, the soft jumping robot yields a different degree of strain.

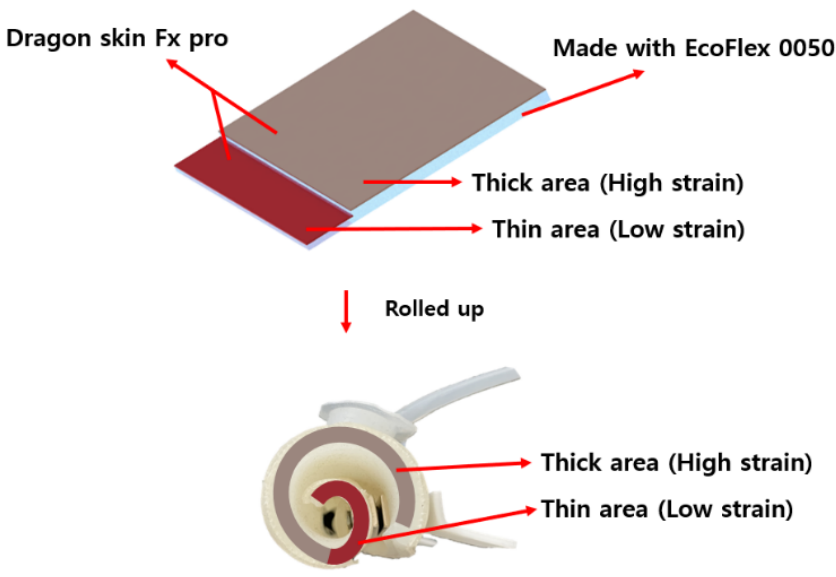

Figure 13. Residual stress control by changing the thickness of the polymer structure.

\subsection{Drive Stabilization of the Soft Robot}

Soft robots manufactured by the above methods are generally round, and therefore, there is a phenomenon of forward rotation during driving or backward rotation during the restoration stage of the soft jumping mechanism. To solve the problem and improve the performance of the soft jumping robot, the front part of the soft jumping robot is equipped with silicon structures in the back and middle, as shown in Figure 14. The soft jumping robot has $0.062 \mathrm{~m}$ long, $0.096 \mathrm{~m}$ wide, and $0.051 \mathrm{~m}$ high. The weight of the soft jumping robot is $0.131 \mathrm{~kg}$.

The attached silicon structures can improve the phenomenon of the rolling forward because of inertia as shown in Figure 15, where the robot can land stably after jumping. The soft jumping robot's back foot does not pull the whole body due to friction with the floor surface of the silicon structure in the middle; instead, the rear foot is pulled to the main body side. 


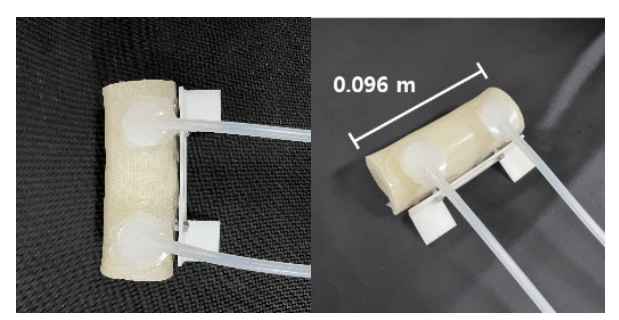

(a)

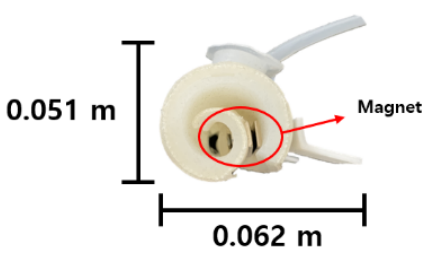

(b)

Figure 14. Final design of soft jumping robot. (a) Attachment position of front foot; (b) magnet for drive stabilization of soft jumping robot.

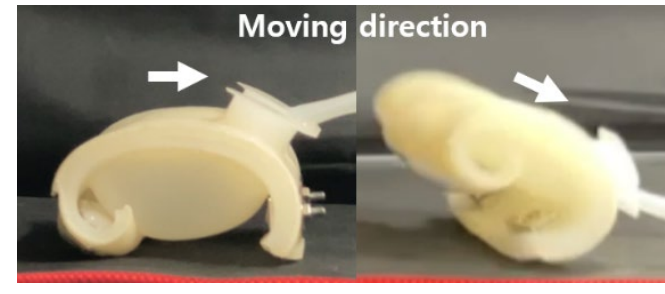

(a)

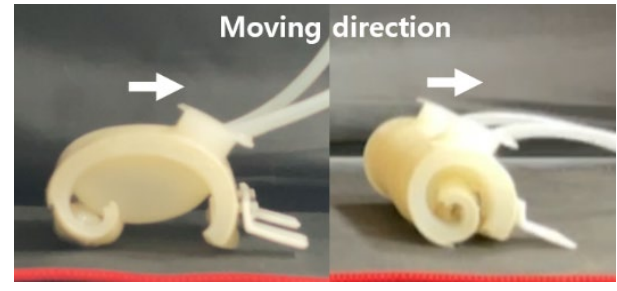

(b)

Figure 15. Comparing landing motion for mounting front foot; (a) Landing motion before mounting front foot. (b) landing motion after mounting front foot type.

\section{Drive Test of Soft Robot}

\subsection{Performance Verification of the Soft Jumping Robots}

To check the dynamic performance of the soft jumping robot, the various conditions of the robot were tested, such as magnet sizes, the amount of air, and the air injecting speed. The original jumping performance has experimented on the flat surface. In addition, the experiments at the various environmental conditions were also conducted to verify the usability of the robot.

The experiment was carried out on a rubber plate with the same specifications, as indicated in Table 3.

Table 3. Conditions for the robot used in the changing direction.

\begin{tabular}{ccc}
\hline $\begin{array}{c}\text { Magnet Size (m) } \\
\text { (Length } \times \text { Width } \times \text { Thickness) }\end{array}$ & Amount of Air & Air Injecting Speed \\
\hline $0.01 \times 0.02 \times 0.003$ & $0.04 \mathrm{~L}$ & $0.0124 \mathrm{~L} / \mathrm{s}$ \\
\hline
\end{tabular}

For the experiment, the soft jumping mechanism located in the lower half of the robot was operated separately. It is easy to switch between the left and right directions as shown in Figure 16.

The average rotation in the left direction excluding the highest and lowest values is $112.5^{\circ} \pm 7.5^{\circ}$ and $105.8^{\circ} \pm 10.8^{\circ}$ to the right. There was a small difference, but it was certainly able to change direction. Data on the experiments are provided in Figure 17.

The experiment on the jump performance of soft jumping robots was conducted by changing the magnet used to investigate the difference in performance, the amount of air injected, and the speed of air injected. The soft jumping robot used in the experiment used the same body.

An experiment was conducted to confirm whether the performance of the soft robot is improved according to the magnetic force installed in the driving part of the soft jumping robot. The maximum jump height and distance of the soft jumping robot were determined by driving the soft jumping robot 10 times from the same starting point. The conditions applied to the soft jumping robot are the same as those shown in Table 4. 


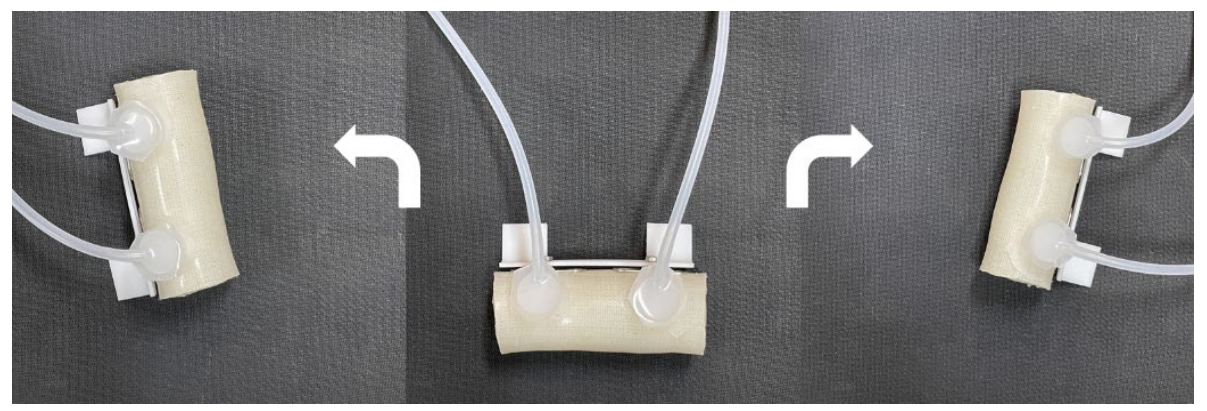

Figure 16. Rotation drive of the soft jumping robot.

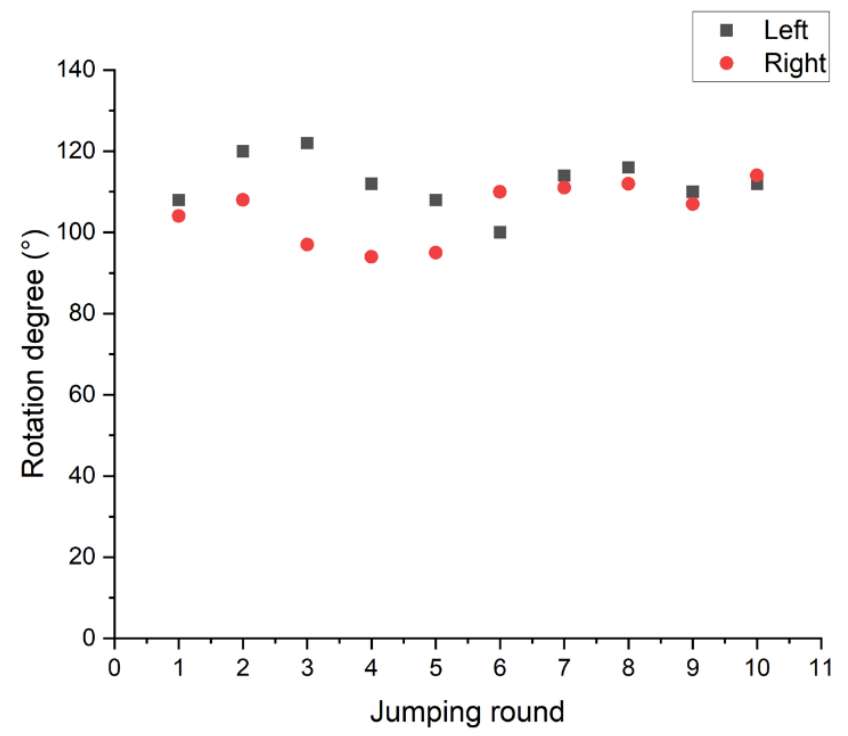

Figure 17. Result of changing direction test.

Table 4. Conditions for the robot used in the comparison of jump forces according to magnetic force test.

\begin{tabular}{ccc}
\hline $\begin{array}{c}\text { Magnet Size (m) } \\
\text { (Length } \times \text { Width } \times \text { Thickness) }\end{array}$ & Amount of Air & Air Injecting Speed \\
\hline $0.01 \times 0.02 \times 0.003$ & $0.04 \mathrm{~L}$ & $0.0124 \mathrm{~L} / \mathrm{s}$ \\
$0.01 \times 0.015 \times 0.003$ & & \\
\hline
\end{tabular}

The result is shown in Figure 18. The performance of the jumping robot improved when the amount and speed of air injected were constant and the magnetic strength was high. In some cases, the experimental values were the same, so the graph was plotted as a single point.

The experiment was carried out while maintaining a constant injection speed to determine the effect of the amount of air supplied to the air chamber inside the soft jumping robot on the performance of the soft jumping robot. The amount of air injected is set at $0.035 \mathrm{~L}$ and $0.04 \mathrm{~L}$, respectively, which does not add a burden on the drive. As in the previous experiment, the soft jumping robot was driven 10 times at the same starting point to determine the maximum jump height and distance of the soft jumping robot. The conditions applied to the soft jumping robot are summarized in Table 5.

The result is shown in Figure 19. The results show that the jumping robot's jump height and jump distance could be adjusted according to the amount of air injected. When the amount of injected air was $0.04 \mathrm{~L}$, the robot jumped higher than $0.035 \mathrm{~L}$, but $0.035 \mathrm{~L}$ jumped farther than $0.04 \mathrm{~L}$. It is because after the yield point of the magnet $(0.035 \mathrm{~L})$ the remaining $0.005 \mathrm{~L}$ further expanded the air chamber to raise the robot's jumping angle. 


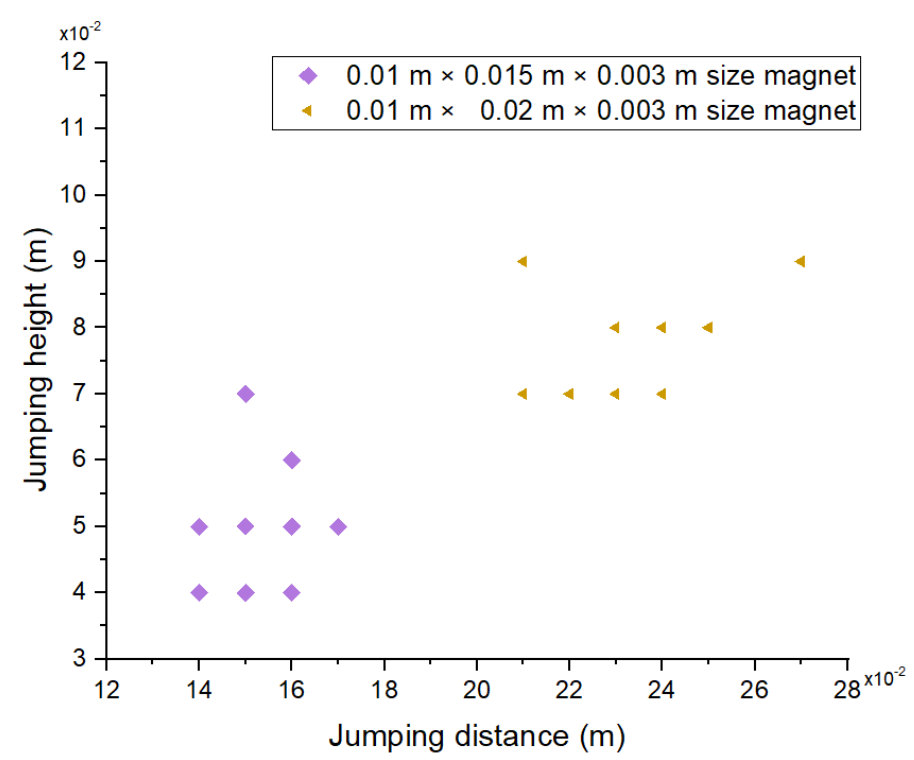

Figure 18. Result of jump forces depending on magnetic force test.

Table 5. Conditions for the robot used in the comparison of jump forces depending on the volume of air injected test.

\begin{tabular}{ccc}
\hline $\begin{array}{c}\text { Magnet Size (m) } \\
(\text { Length } \times \text { Width } \times \text { Thickness) }\end{array}$ & Amount of Air & Air Injecting Speed \\
\hline $0.01 \times 0.02 \times 0.003$ & $0.035 \mathrm{~L}$ & $0.0124 \mathrm{~L} / \mathrm{s}$ \\
\hline
\end{tabular}

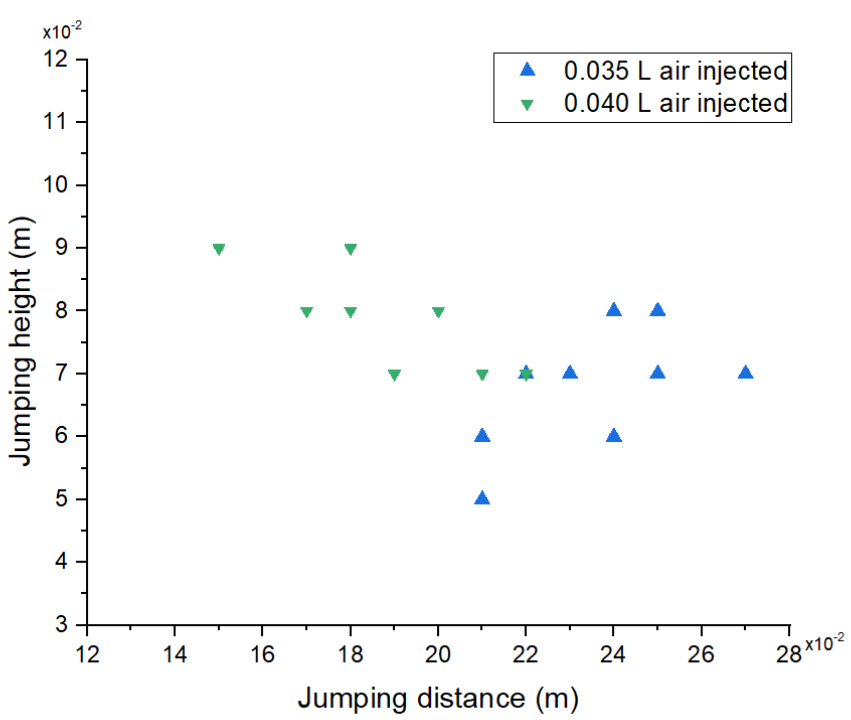

Figure 19. Result of comparison of the jump forces depending on the volume of air injected test.

The experiment was carried out by maintaining the magnet installed in the drive and the amount of air supplied to find out the effect of air injection speed on the performance of the soft jumping robot. Air injecting speed was set to $0.0124 \mathrm{~L} / \mathrm{s}$ and $0.025 \mathrm{~L} / \mathrm{s}$, respectively, to the extent that it did not burden the driving part. As in the previous experiment, the maximum jump height and distance of the soft jumping robot were determined by driving the soft jumping robot 10 times. The conditions applied to the soft jumping robot are listed in Table 6. 
Table 6. Conditions for the robot used in the comparison of jump forces depending on the air injecting speed.

\begin{tabular}{ccc}
\hline $\begin{array}{c}\text { Magnet Size (m) } \\
(\text { Length } \times \text { Width } \times \text { Thickness) }\end{array}$ & Amount of Air & Air Injecting Speed \\
\hline $0.01 \times 0.02 \times 0.003$ & $0.040 \mathrm{~L}$ & $0.0124 \mathrm{~L} / \mathrm{s}$ \\
& & $0.025 \mathrm{~L} / \mathrm{s}$ \\
\hline
\end{tabular}

The results are shown in Figure 20. The results indicate that the performance of the jumping robot can be improved when the amount of air injected, and the magnetic force of the permanent magnet installed are constant and the speed of air injected through the drive is high.

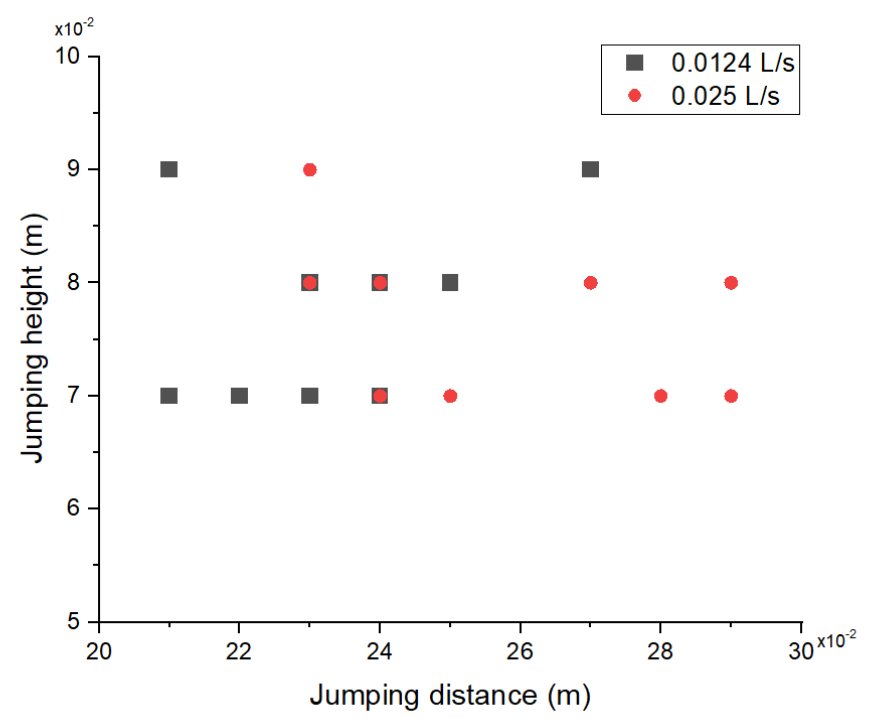

Figure 20. Comparison of jump forces depending on the air injecting speed.

The results of the driving tests show that the driving performance of soft-jumping robots using the soft-jumping mechanism produced in this paper are considerably affected by air injection. This is because the faster the air is injected from the magnetic yield point, the faster the energy is formed inside the air chamber, and the faster the driving occurs after the magnetic yield. Further, it was confirmed that the smaller the attached magnet, the lower is the driving performance of the soft jumping robot, and the more air it injects, the better is the performance.

\subsection{Driving Tests under a Variety of Environments}

The conditions of the soft robot used for this experiment are summarized in Table 3.

The experiment was conducted on a flat surface, a puddle, and $10^{\circ}$ slope condition, as shown in Figure 21. The figure shows the jumping drive of a soft jumping robot on a flat surface. The jumping robot has a cycle of about $3 \mathrm{~s}$, and when the soft jumping robot starts jumping the angle between the soft jumping robot and the ground is about $60^{\circ}$. It was possible to jump stably without being overturned.

Comparative driving experiments were conducted on pools and flatlands as shown in Figure 22 to confirm the jumping stability of the soft jumping robots. The driving performance of the soft jumping robot was lower than that of the flat ground because of the water resistance in the puddle; however, the deterioration of the driving performance did not affect the driving on the flat surface. It is confirmed that a soft jumping mechanism can be driven continuously for a long time without fail because it does not use complex structures or electronic components and does not interfere with moisture. In the puddle, 
the jumping height of the robot was about $0.07 \mathrm{~m}$ and the jumping distance was about $0.02 \mathrm{~m}$ when the driving condition was the same as Table 3 .

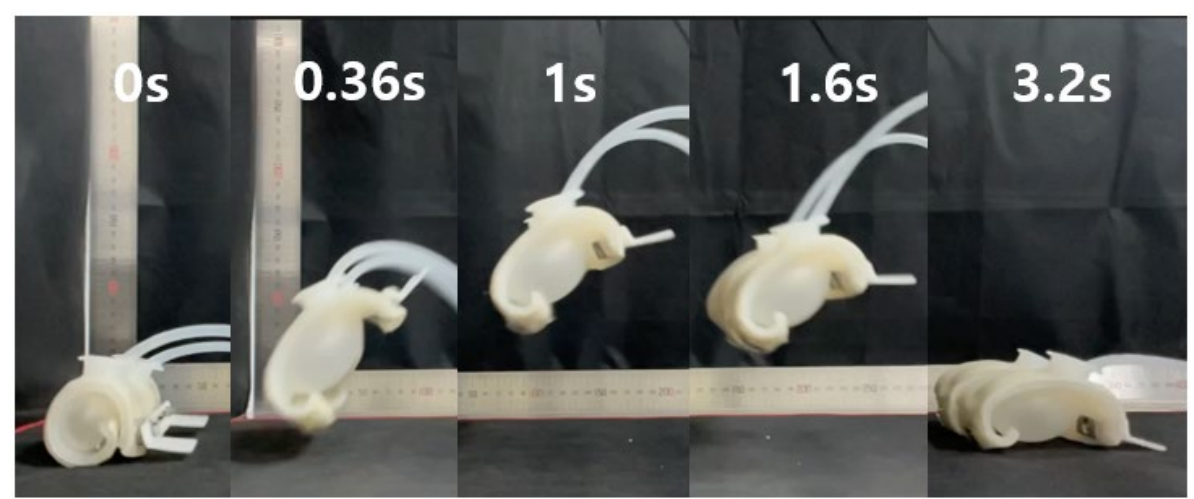

Figure 21. Drive motion of soft jumping robot.
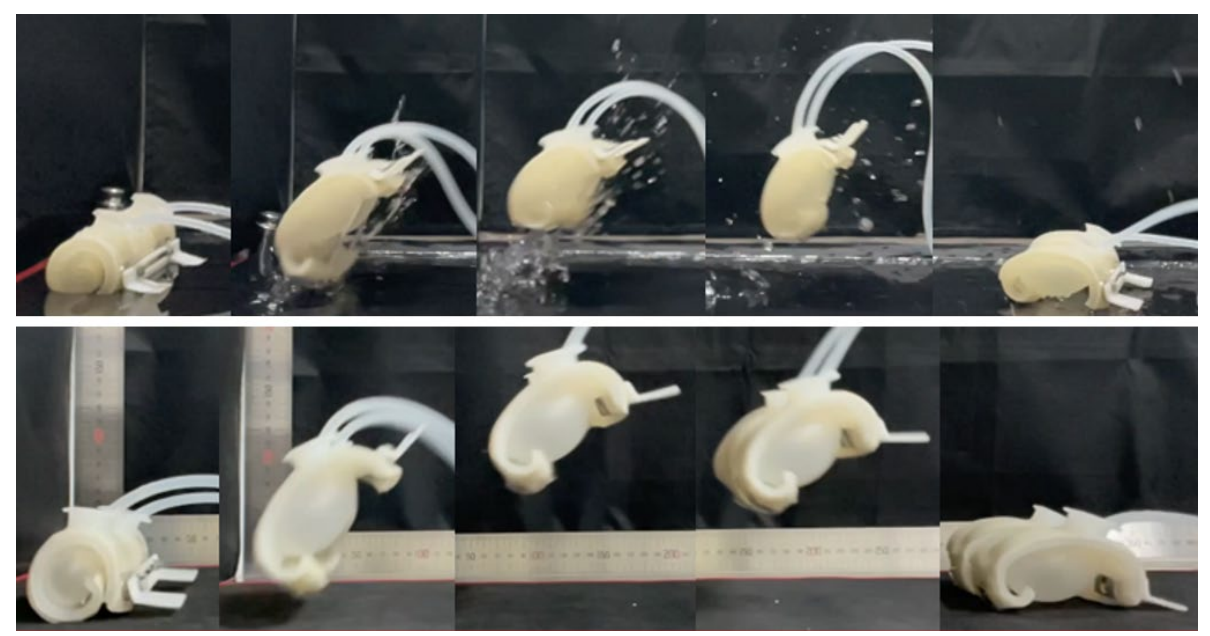

Figure 22. Comparison of the jumping motion of soft jumping robots on water pools and flat land.

Figure 23 shows the driving experiment conducted to evaluate the driving performance of a soft jumping robot on the $10^{\circ}$ slope. However, it was found that the angle of the soft jumping robot's body at the beginning of jump on a flat surface was about $60^{\circ}$, while the $10^{\circ}$ angle of the existing ground caused the soft jumping robot to drive at a higher angle than on a flat surface. Soft jumping robot jumped well on the $10^{\circ}$ slope. When soft jumping robot driving in a puddle, lowering the jump force has been effective in increasing stability. In the $10^{\circ}$ slope condition, the jumping height of the robot was about $0.07 \mathrm{~m}$ and the jumping distance was about $0.015 \mathrm{~m}$ when the driving condition was the same as Table 3. See Supplementary Materials.

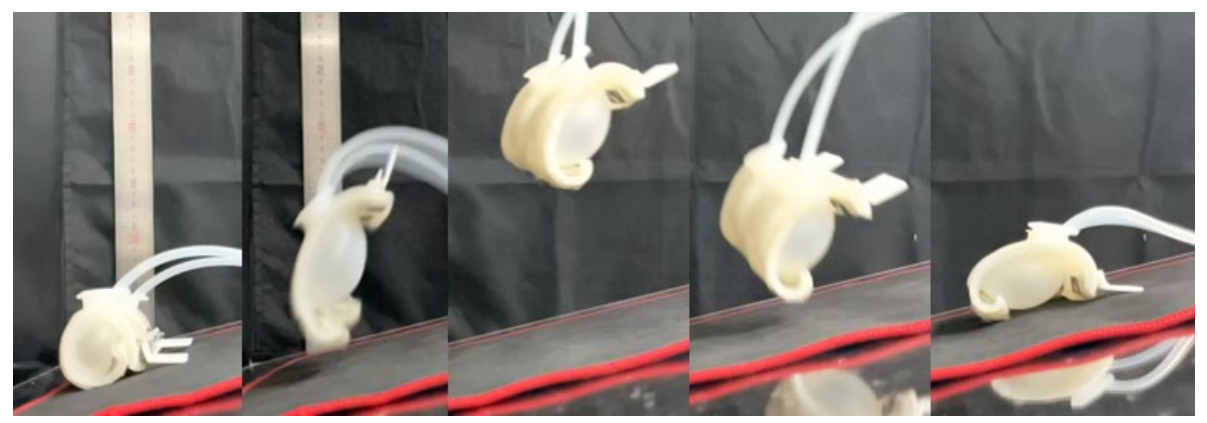

Figure 23. Jumping motion of soft jumping robots on $10^{\circ}$ slope. 


\section{Conclusions}

A soft morphing substrate manufacturing method was presented in this study. Using this method and magnetic yield point, we produced soft jumping robots that can store, release, and restore energy, and can change direction and jump in various environments to confirm the driving performance of soft jumping robots. Based on the results of the experiment, the thickness of the polymer structure was adjusted to suit the shape of the soft jumping robot, and the deformation rate of each part of the soft jumping robot was obtained. To confirm the driving performance of a soft robot with a soft jumping mechanism, 10 driving experiments were conducted. The experimental results indicate that the stronger the permanent magnet installed in the soft robot, the more air is injected, and the faster the air is injected, the higher is the performance under the same conditions. Soft jumping robots were tested on puddle and the $10^{\circ}$ slope to investigate the possibility of driving under various environments. The results of the experiment confirmed that there was no overturning or damage when the robot moved in three different environments. Further, there was no difficulty in driving repeatedly.

In the future, adjusting the force of the magnet and the shape of the air chamber will reliably improve the jumping performance of the soft robot. At present, the pneumatic actuation part was not embedded in the soft robot. If the performance of the robot increases, the additional parts such as the pneumatic actuation part can be mounted into the soft jumping robot. It is necessary to add the additional parts compactly. Then the utilization of robots will increase even more.

Supplementary Materials: The following are available online at https://youtu.be/LJp1ld4btrE, Video: Soft Jumping Robot.

Author Contributions: G.-H.J.; investigation, G.-H.J. and Y.-J.P.; Conceptualization, methodology, validation, resources, writing — original draft preparation, writing-review and editing, project administration, funding acquisition. Both authors have read and agreed to the published version of the manuscript.

Funding: This research was supported by Basic Science Research Program through the National Research Foundation of Korea (NRF) funded by the Ministry of Education(2020R111A3073575) and by the National Research Foundation of Korea (NRF) Grant funded by the Korean Government (MSIT) (No.NRF-2016R1A5A1938472).

Institutional Review Board Statement: Not applicable.

Informed Consent Statement: Not applicable.

Data Availability Statement: Not applicable.

Acknowledgments: Kyu-Jin Cho and Jun-Young Lee; thank you for your advice on the bistable mechanism.

Conflicts of Interest: The authors declare no conflict of interest.

\section{References}

1. Bledt, G.; Powell, M.J.; Katz, B.; Carlo, J.D.; Wensing, P.M.; Kim, S. MIT Cheetah 3: Design and Control of a Robust, Dynamic Quadruped Robot. In Proceedings of the 2018 IEEE/RSJ International Conference on Intelligent Robots and Systems (IROS), Madrid, Spain, 1-5 October 2018; pp. 2245-2252.

2. Wooden, D.; Malchano, M.; Blankespoor, K.; Howardy, A.; Rizzi, A.A.; Raibert, M. Autonomous Navigation for BigDog. In Proceedings of the 2010 IEEE International Conference on Robotics and Automation, Anchorage, AK, USA, 3-8 May 2010; pp. $4736-4741$.

3. Han, M.-W.; Kim, M.-S.; Ahn, S.-H. Shape Memory Textile Composites with Multi-Mode Actuations for Soft Morphing Skins. Compos. Part B Eng. 2020, 198, 108170. [CrossRef]

4. Umedachi, T.; Vikas, V.; Trimmer, B.A. Softworms: The Design and Control of Non-Pneumatic, 3D-Printed, Deformable Robots. Bioinspir. Biomim. 2016, 11, 025001. [CrossRef]

5. Zhang, Y.; Zhang, N.; Hingorani, H.; Ding, N.; Wang, D.; Yuan, C.; Zhang, B.; Gu, G.; Ge, Q. Fast-Response, Stiffness-Tunable Soft Actuator by Hybrid Multimaterial 3D Printing. Adv. Funct. Mater. 2019, 29, 1806698. [CrossRef]

6. Liu, Y.; Shaw, B.; Dickey, M.D.; Genzer, J. Sequential Self-Folding of Polymer Sheets. Sci. Adv. 2017, 3, e1602417. [CrossRef] [PubMed] 
7. Kim, H.-I.; Han, M.-W.; Song, S.-H.; Ahn, S.-H. Soft Morphing Hand Driven by SMA Tendon Wire. Compos. Part B Eng. 2016, 105, 138-148. [CrossRef]

8. Shepherd, R.F.; Stokes, A.A.; Freake, J.; Barber, J.; Snyder, P.W.; Mazzeo, A.D.; Cademartiri, L.; Morin, S.A.; Whitesides, G.M. Using Explosions to Power a Soft Robot. Angew. Chem. Int. Ed. 2013, 52, 2892-2896. [CrossRef] [PubMed]

9. Tolley, M.T.; Shepherd, R.F.; Karpelson, M.; Bartlett, N.W.; Galloway, K.C.; Wehner, M.; Nunes, R.; Whitesides, G.M.; Wood, R.J. An Untethered Jumping Soft Robot. In Proceedings of the 2014 IEEE/RSJ International Conference on Intelligent Robots and Systems, Chicago, IL, USA, 14-18 September 2014; pp. 561-566.

10. Bartlett, N.W.; Tolley, M.T.; Overvelde, J.T.B.; Weaver, J.C.; Mosadegh, B.; Bertoldi, K.; Whitesides, G.M.; Wood, R.J. A 3D-Printed, Functionally Graded Soft Robot Powered by Combustion. Science 2015, 349, 161-165. [CrossRef] [PubMed]

11. Wehner, M.; Truby, R.L.; Fitzgerald, D.J.; Mosadegh, B.; Whitesides, G.M.; Lewis, J.A.; Wood, R.J. An Integrated Design and Fabrication Strategy for Entirely Soft, Autonomous Robots. Nature 2016, 536, 451-455. [CrossRef] [PubMed]

12. Yang, X.; Chang, L.; Pérez-Arancibia, N.O. An 88-Milligram Insect-Scale Autonomous Crawling Robot Driven by a Catalytic Artificial Muscle. Sci. Robot. 2020, 5, eaba0015. [CrossRef]

13. Jung, G.; Casarez, C.S.; Jung, S.; Fearing, R.S.; Cho, K. An Integrated Jumping-Crawling Robot Using Height-Adjustable Jumping Module. In Proceedings of the 2016 IEEE International Conference on Robotics and Automation (ICRA), Stockholm, Sweden, 16-21 May 2016; pp. 4680-4685.

14. Haldane, D.W.; Plecnik, M.; Yim, J.K.; Fearing, R.S. A Power Modulating Leg Mechanism for Monopedal Hopping. In Proceedings of the 2016 IEEE/RSJ International Conference on Intelligent Robots and Systems (IROS), Daejeon, Korea, 9-14 October 2016; pp. 4757-4764.

15. Woodward, M.A.; Sitti, M. MultiMo-Bat: A Biologically Inspired Integrated Jumping-Gliding Robot. Int. J. Robot. Res. 2014, 33, 1511-1529. [CrossRef]

16. Jiang, F.; Zhao, J.; Kota, A.K.; Xi, N.; Mutka, M.W.; Xiao, L. A Miniature Water Surface Jumping Robot. IEEE Robot. Autom. Lett. 2017, 2, 1272-1279. [CrossRef]

17. Kenneally, G.; De, A.; Koditschek, D.E. Design Principles for a Family of Direct-Drive Legged Robots. IEEE Robot. Autom. Lett. 2016, 1, 900-907. [CrossRef]

18. Noh, M.; Kim, S.; An, S.; Koh, J.; Cho, K. Flea-Inspired Catapult Mechanism for Miniature Jumping Robots. IEEE Trans. Robot. 2012, 28, 1007-1018. [CrossRef]

19. Tang, Y.; Chi, Y.; Sun, J.; Huang, T.-H.; Maghsoudi, O.H.; Spence, A.; Zhao, J.; Su, H.; Yin, J. Leveraging Elastic Instabilities for Amplified Performance: Spine-Inspired High-Speed and High-Force Soft Robots. Sci. Adv. 2020, 6, eaaz6912. [CrossRef]

20. Liu, G.-H.; Lin, H.-Y.; Lin, H.-Y.; Chen, S.-T.; Lin, P.-C. A Bio-Inspired Hopping Kangaroo Robot with an Active Tail. J. Bionic. Eng. 2014, 11, 541-555. [CrossRef]

21. Zaitsev, V.; Gvirsman, O.; Ben Hanan, U.; Weiss, A.; Ayali, A.; Kosa, G. A Locust-Inspired Miniature Jumping Robot. Bioinspir. Biomim. 2015, 10, 066012. [CrossRef] [PubMed]

22. Wang, M.; Zang, X.; Fan, J.; Zhao, J. Biological Jumping Mechanism Analysis and Modeling for Frog Robot. J. Bionic Eng. 2008, 5, 181-188. [CrossRef]

23. Ache, J.M.; Matheson, T. Passive Joint Forces Are Tuned to Limb Use in Insects and Drive Movements without Motor Activity. Curr. Biol. 2013, 23, 1418-1426. [CrossRef]

24. Baek, S.-M.; Yim, S.; Chae, S.-H.; Lee, D.-Y.; Cho, K.-J. Ladybird Beetle—Inspired Compliant Origami. Sci. Robot. 2020, 5, eaaz6262. [CrossRef]

25. Chen, Z.; Majidi, C.; Srolovitz, D.J.; Haataja, M. Tunable Helical Ribbons. Appl. Phys. Lett. 2011, 98, 011906. [CrossRef]

26. Han, M.-W.; Ahn, S.-H. Blooming Knit Flowers: Loop-Linked Soft Morphing Structures for Soft Robotics. Adv. Mater. 2017, 29, 1606580. [CrossRef] [PubMed]

27. Franinović, K.; Franzke, L. Shape Changing Surfaces and Structures: Design Tools and Methods for Electroactive Polymers. In Proceedings of the 2019 CHI Conference on Human Factors in Computing Systems, Glasgow, Scotland, UK, 4-9 May 2019; pp. 1-12.

28. Kim, S.; Koh, J.; Cho, M.; Cho, K. Towards a Bio-Mimetic Flytrap Robot Based on a Snap-through Mechanism. In Proceedings of the 2010 3rd IEEE RAS EMBS International Conference on Biomedical Robotics and Biomechatronics, Tokyo, Japan, 26-29 September 2010; pp. 534-539.

29. Shahinpoor, M. Biomimetic Robotic Venus Flytrap (Dionaea Muscipula Ellis) Made with Ionic Polymer Metal Composites. Bioinspir. Biomim. 2011, 6, 046004. [CrossRef] [PubMed]

30. Shepherd, R.F.; Ilievski, F.; Choi, W.; Morin, S.A.; Stokes, A.A.; Mazzeo, A.D.; Chen, X.; Wang, M.; Whitesides, G.M. Multigait Soft Robot. Proc. Natl. Acad. Sci. USA 2011, 108, 20400-20403. [CrossRef] [PubMed]

31. Vokoun, D.; Beleggia, M.; Heller, L.; Šittner, P. Magnetostatic Interactions and Forces between Cylindrical Permanent Magnets. J. Magn. Magn. Mater. 2009, 321, 3758-3763. [CrossRef] 